\title{
ASPECTOS ICONOGRÁFICOS INFERNAIS EM INCUNÁBULOS DA DIVINA COMÉDIA
}

\author{
Paula Ferreira Vermeersch ${ }^{1}$
}

\section{Resumo}

Esse artigo pretende ser uma introdução a uma pesquisa, a partir dos incunábulos da Divina Comédia do acervo da Biblioteca Newberry, de Chicago, EUA, às iconografias renascentistas do poema de Dante. O objetivo é delinear um estudo introdutório e comparativo a alguns aspectos iconográficos do Inferno, nas três primeiras edições ilustradas do poema.

Palavras-chave: Iconografia Renascentista- Incunábulos da Comédia- Inferno

\begin{abstract}
:
This article is intended to be an introduction for a research with the Newberry Library's incunabulae on Dante's Divine Comedy Renaissance iconographies. The objective is to delineate an introductory and comparative study of some of the Hell's iconographic aspects, in the three first illustrated editions of the poem.
\end{abstract}

Keywords: Renaissance Iconography- Dante’s incunabulae- Hell

O objetivo deste texto e da comunicação ${ }^{2}$ é apresentar sumariamente alguns aspectos da iconografia dantesca renascentista, nos incunábulos do poema de Dante, e examinar a importância do conjunto de desenhos que o pintor florentino Sandro Botticelli realizou, entre as décadas de 1480 e 1490, na história dessas ilustrações pioneiras.

A primeira edição da Divina Comédia foi publicada na cidade úmbria de Foligno, em1472, por obra de um cônego alemão chamado Johann Neumeister, discípulo de Gutenberg ${ }^{3}$. Sem comentário, a edição possui uma decoração simples, feita à mão, de iniciais coloridas e guirlandas na margem inferior da página primeira de cada Canto. Considerando as dificuldades técnicas dessa primeira fase da história da impressão ${ }^{4}$, é de se ressaltar o desejo de Neumeister em apresentar o texto do poema, já consagrado pelas cópias manuscritas, algumas decoradas com luxo, de forma agradável e visualmente atraente. A tipografia escolhida, do tipo humanístico, reforça a clareza e a importância da pioneira edição.

Meses depois, no mesmo ano, saem edições nas cidades de Mântua e Veneza. Em 1477 e 1478, em Nápoles, são publicados mais dois livros, baseados na de Foligno; e nos mesmos anos, editores de Veneza e Milão apresentam mais dois incunábulos da Comédia ${ }^{5}$.

\footnotetext{
1 doutoranda em Teoria e História Literária, Instituto de Estudos da Linguagem/ IEL-Unicamp, bolsista FAPESP.

2 Este texto não teria surgido sem o auxílio da Fundação de Amparo à Pesquisa do Estado de São Paulo, FAPESP, sob a forma de uma bolsa de doutorado. Graças a essa bolsa, uma viagem a Chicago, EUA, possibilitou o acesso aos acervos da Biblioteca Newberry e à Coleção Dante, da Universidade de NotreDame, South Bend, Indiana. Meus agradecimentos aos funcionários de ambas as instituições. O texto foi escrito às margens do Michigan; saudades.

3 ALIGHIERI, Dante. La Commedia. Foligno: Johann Neumeister, 1472 . Editio Princeps

${ }^{4}$ FEBVRE, Lucien, MARTIN, Henri-Jean. O aparecimento do livro. São Paulo: Unesp, Hucitec, 1992

5 Tais dados são fornecidos pelas equipes da Biblioteca Newberry e Coleções Especiais da Universidade de Notre-Dame no site http://www.italnet.nd.edu/Dante/text/1472.foligno.html. É importante notar que as duas coleções norte-americanas não possuem as edições de 1472 de Mântua e Veneza, as napolitanas, a veneziana de 1477 e a milanesa de 1478; portanto, tais incunábulos não foram consultados.
} 
Os centros produtores de manuscritos do poema, fora da Toscana, voltam a se destacar nas iniciativas pioneiras de difusão da obra de Dante.

Em 1477, em Veneza, a primeira edição com comentário vem à luz, sob a responsabilidade do editor alemão Windelin de Speyer ${ }^{6}$. O editor imprimiu a "Vida de Dante", de Bocaccio, como introdução, o "Credo"de Dante, textos de Busone da Gubbio, um soneto tradicionalmente atribuído a Bocaccio ( que contém um verso famoso, "Dante Alighieri son, Minerva oscura") e um de sua própria autoria, como colofão. Já o comentário, identificado no livro como o de Benvenuto da Imola, de 1380, na verdade é o de Jacopo della Lana, do início do século XV. O site Dante Renaissance on Print ${ }^{7}$ afirma que Windelin de Speyer intencionalmente identificou o comentário de forma errônea, por acreditar que o nome de Benvenuto seria melhor aceito pelos leitores.

A edição de 1477 também traz outra novidade: os textos foram publicados em escrita gótica. A convenção dos manuscritos reservava tal escrita para os textos sacros; já os profanos viriam em escrita humanística. Há de se notar que nos manuscritos para a Comédia tais estilos de caligrafia coexistem: desde os Danti del Cento, de Francesco di Ser Nardo, de caligrafia gótica simplificada, até a escrita humanística do Códex Botticelli, o poema de Dante foi considerado sacro, e profano.

Em termos de iconografia, porém, nem a Editio Princeps nem a edição veneziana de 1477 possuem material. Os incunábulos ficariam muito aquém dos coloridos manuscritos se os florentinos não tivessem, em 1481, entrado no debate Dante com a edição de Niccolò di Lorenzo della Magna e suas ilustrações dos Cantos do Inferno.

A relação entre o conjunto de desenhos de Botticelli e a edição florentina da Comédia ainda não se encontra esclarecida de todo. Lamberto Donati ${ }^{8}$ e Peter Keller ${ }^{9}$ discutem vários aspectos dessa relação. Resumindo, tanto Donati quanto Keller perguntam se as ilustrações da edição de 1481 constituíram-se num projeto abortado.

Se a resposta é afirmativa, por quais razões? Porque Landino entregou um exemplar sem ilustrações para a Signoria? As dificuldades técnicas em imprimir o texto mais as ilustrações fizeram com que o livro não ficasse pronto a tempo, ou Landino considerou as gravuras indignas de serem apresentadas oficialmente, junto ao seu comentário? Limitações do gravador ou desordem de Botticelli, como alega Vasari? Ou a seguinte hipótese: contraste entre o comentário literário de Landino e o visual de Botticelli, além do projeto editorial?

Yvonne Bâtard cita a menção que Vasari faz a Baccio Baldini na vida de Marcantonio Raimondi, quando trata de Fininguerra: "Fu seguitato costui ( Fininguerra) da Baccio Baldini orefice fiorentino, il quale non avendo molto disegno, tutto quelle che fece fu con invenzione e disegno di Sandro Botticelli’"10.

Ottaviano Scoto, de importante família de editores, lançou em 1484, em Veneza, uma edição muito bem-cuidada, do ponto de vista tipográfico, da Comédia com o

\footnotetext{
${ }^{6}$ ALIGHIERI, Dante. La Commedia. Venezia: Windelin de Speyer, 1477

${ }^{7}$ http://www.italnet.nd.edu/Dante/text/1477.venice.html

${ }^{8}$ DONATI, Lamberto. Il Botticelli e le prime illustrazioni della Divina Commedia. Firenze: Leo S. Olschki Editore, 1962

9 KELLER, Peter. "The Engravings in the 1481 Edition of the Divine Comedy", in SCHULZE ALTCAPPENBERG, Hein-Th. Sandro Botticelli: the drawings for Dante's Divine Comedy. London: Royal Academy of Arts, 2000

${ }^{10}$ BÂTARD, Yvonne. Les dessins de Sandro Botticelli pour La divine Comédie. Paris : O. Perrin, 1952, pg.5.
} 
comentário de Landino ${ }^{11}$, mas sem ilustrações. A edição de Scoto marca a difusão do comentário de Landino, reeditado nas próximas iniciativas até o final do século seguinte.

O projeto de ilustrar um incunábulo da Comédia é retomado em Brescia, pelo editor Bonino de Bonini ${ }^{12}$. As iconografias utilizadas pelos gravadores ( é nítido, no livro, que pelo menos três gravadores se encarregaram da tarefa) são baseadas na edição florentina de 1481, e assim como no caso desta os artistas não concluíram a tarefa de ilustrar os três Cantos.

Paul Schubring, em estudo de iconografia dantesca que segue o texto do poema, com o auxílio de reproduções das gravuras de Brescia ${ }^{13}$, aponta para a possibilidade dos artesãos serem de origem germânica. De qualquer forma, os ilustradores seguiram de perto as indicações botticellianas da edição florentina: as indicações topográficas, as iconografias, e principalmente o pathos em várias cenas (exemplo da cena seqüencial do encontro com Cérbero) atestam que o "projeto Botticelli"( os desenhos e as gravuras) representou ponto de mutação na tradição de ilustração para a Comédia: as edições irão seguir as gravuras florentinas, não mais a tradição dos manuscritos. Bonino de Bonini editou a primeira das tentativas, e seu belo projeto permaneceu inacabado, mesmo nas gravuras que chegaram a ser publicadas.

Em 1491, surge o primeiro incunábulo totalmente ilustrado da Comédia, em Veneza, por obra do editor Pietro di Piasi Cremonese ${ }^{14}$. Neste projeto de ilustração bemsucedido, Cremonese optou por pequenas gravuras, pequenas cenas em cada Canto, ao invés de gravuras de página inteira, como no caso da edição de Bonini; e retomou a idéia do pequeno formato, de Niccolò della Magna, mas resolveu o problema enfrentado por este, que, impossibilitado de imprimir as gravuras com o texto, teve que colá-las nas páginas.

As gravuras, quase vinhetas de cada Canto, seguem de perto as indicações de suas antecessoras de Florença e Brescia, nos quesitos iconografia e seqüências narrativas, e serão reimpressas pelos anos sucessivos em Veneza ${ }^{15}$.

Num belo livro com reproduções em gravuras das ilustrações das edições de Florença, 1481, Brescia, 1487, e Veneza, 1491, feitas pela Regia Scuola Tipografica e di Arti affini di Torino, em $1911^{16}$, pode-se observar lado a lado as gravuras e constatar a influência decisiva da edição florentina. É o caso da ilustração para o Inferno, Canto VI, que mostra a ação de Virgílio ao amassar terra para jogar em Cérbero. O ilustrador do pathos em Brescia segue Firenze 1481.

O monstro Gerião de 81 é maior e mais aterrorizante que de 87, e o de 91 retoma a tradição dos manuscritos em fazer do monstro algo pequeno e desprezível.Nesse sentido, Brescia é mais próxima de Florença 1481.

Consultando os livros, pode-se perceber algumas das dificuldades inerentes a esses projetos. Numa época em que cada página deveria ser montada à parte, e à mão, artesãos e editores depararam-se com o seguinte problema: como encaixar o poema de Dante, com

\footnotetext{
11 ALIGHIERI, Dante. La Commedia. Veneza: Ottaviano Scoto, 1484

12 ALIGHIERI, Dante. La Commedia. Brescia: Bonino de Bonini, 1487

13 SCHUBRING, Paul. Illustrationen zu Dantes Gottlicher Komodie. Italien, 14. bis 16. Jahrhundert. Wien: Amalthea-Verlag, 1931

14 ALIGHIERI, Dante. La Commedia. Veneza: Pietro di Piasi Cremonese, 1491

15 São os casos de ALIGHIERI, Dante. La Commedia.Veneza: Bernardino Benali e Mateo di Codeca da Parma, 1492, e Veneza: Mateo di Codeca da Parma, 1493

${ }^{16}$ Figure Quattrocentesche della Divina Commedia. Torino: Regia Scuola Tipografica e di Arti affini di Torino nella Stamperia quattrocentesca del Borgo Medievale, 1921
} 
comentários, introduções mais ilustrações, nos grandes carimbos que afinal eram as páginas.

\section{Bibliografia}

ALIGHIERI, Dante. La Commedia. Foligno: Johann Neumeister, 1472 . Editio Princeps Venezia: Windelin of Speyer, 1477

.Firenze: Niccolò della Magna, 1481

.Veneza:Ottaviano Scoto, 1484

.Brescia: Bonino de Bonini, 1487

.Veneza: Pietro di Piasi Cremonese, 1491

.Veneza: Bernardino Benali e Mateo di Codeca da Parma, 1492

.Veneza: Mateo di Codeca da Parma, 1493

. Le Terze Rime de Dante.Veneza: Aldus Manutius, 1502

Commedia di Dante insieme con uno dialogo circa il sito et misure

dello Inferno. Firenze: Fillipo Giunta, 1506

.Veneza: Jacopo da Borgofranco e Lucantonio Giunta, 1529

1999

A Divina Comédia. Inferno. Tradução de Ítalo Mauro. São Paulo: Ed.34,

BÂTARD, Yvonne. Les dessins de Sandro Botticelli pour La divine Comédie. Paris : O. Perrin, 1952

COLONNA, Francesco. Hypnerotomachia Poliphili. Veneza: Aldus Manutius,1499

DAVIES, Martin, GOLDFINCH, John (ed.). Vergil. A Census of Printed Editions 1469-1500. London: British Library, 1992

DONATI, Lamberto. Incisioni Fiorentine del Quattrocento. Bergamo: Istituto Italiano D’Arte Grafiche, 1954

.Il Botticelli e le prime illustrazioni della Divina Commedia. Firenze: Leo S. Olschki Editore, 1962

FEBVRE, Lucien, MARTIN, Henri-Jean. O aparecimento do livro. São Paulo: Unesp, Hucitec, 1992.

Figure Quattrocentesche della Divina Commedia. Torino: Regia Scuola Tipografica e di Arti affini di Torino nella Stamperia quattrocentesca del Borgo Medievale, 1921

GOLDSCHMIDT, Ernst Ph. The Printed Book of the Renaissance. Amsterdam: Gérard Th. Van Heusden Publisher, 1974

KELLER, Peter. "The Engravings in the 1481 Edition of the Divine Comedy", in SCHULZE ALTCAPPENBERG, Hein-Th. Sandro Botticelli: the drawings for Dante's Divine Comedy. London: Royal Academy of Arts, 2000

SCHUBRING, Paul. Illustrationen zu Dantes Gottlicher Komodie. Italien, 14. bis 16. Jahrhundert. Wien: Amalthea-Verlag, 1931

VIRGÍLIO.Opera. Strassburg: Johann Mentelin, 1470

Opera. Venezia, 1472

.Opera. Firenze: Printer of Vergilius, 1487 
.Opera. Nuremberg: Anton Koberger, 1492

.Opera. Venezia, 1493

.Bucolica. Paris: Andre Beccardi, 1495 